\title{
(息)
}

Citation:

Hanley, B (2015) Pacing profiles and pack running at the IAAF World Half Marathon Championships. Journal of Sports Sciences, 33 (11). 1189 - 1195 (7). ISSN 0264-0414 DOI: https://doi.org/10.1080/02640414.2014.988742

Link to Leeds Beckett Repository record:

https://eprints.leedsbeckett.ac.uk/id/eprint/376/

Document Version:

Article (Accepted Version)

The aim of the Leeds Beckett Repository is to provide open access to our research, as required by funder policies and permitted by publishers and copyright law.

The Leeds Beckett repository holds a wide range of publications, each of which has been checked for copyright and the relevant embargo period has been applied by the Research Services team.

We operate on a standard take-down policy. If you are the author or publisher of an output and you would like it removed from the repository, please contact us and we will investigate on a case-by-case basis.

Each thesis in the repository has been cleared where necessary by the author for third party copyright. If you would like a thesis to be removed from the repository or believe there is an issue with copyright, please contact us on openaccess@leedsbeckett.ac.uk and we will investigate on a case-by-case basis. 


\section{Pacing profiles and pack running at the IAAF World Half Marathon}

\section{Championships}

Brian Hanley

School of Sport, Carnegie Faculty, Headingley Campus, Leeds Beckett University, United

Kingdom

Correspondence details:

Brian Hanley,

Fairfax Hall,

Headingley Campus,

Leeds Beckett University,

LS6 3QS,

United Kingdom.

Telephone: +441138123577

Fax: +44 1132833170

Email: b.hanley@leedsbeckett.ac.uk

Running title: Pacing and packing in half marathon running

Keywords: Elite-standard athletes, endurance running, fatigue, race tactics, sprint finish 


\begin{abstract}
The aim of this study was to describe the pacing profiles and packing behaviour of athletes competing in the IAAF World Half Marathon Championships. Finishing and split times were collated for 491 men and 347 women across six championships. The mean speeds for each intermediate $5 \mathrm{~km}$ and end $1.1 \mathrm{~km}$ segments were calculated, and athletes grouped according to finishing time. The best men and women largely maintained their split speeds between 5 $\mathrm{km}$ and $15 \mathrm{~km}$, whereas slower athletes had decreased speeds from $5 \mathrm{~km}$ onwards. Athletes were also classified by the type of packing behaviour in which they engaged. Those who ran in packs throughout the race had smaller decreases in pace than those who did not, or who managed to do so only to $5 \mathrm{~km}$. While some athletes' reduced speeds from 15 to $20 \mathrm{~km}$ might have been caused by fatigue, it was also possibly a tactic to aid a fast finish that was particularly beneficial to medallists. Those athletes who ran with the same competitors throughout sped up most during the finish. Athletes are advised to identify rivals likely to have similar abilities and ambitions and run with them as part of their pre-race strategy.
\end{abstract}




\section{INTRODUCTION}

Over the past three decades, the half marathon has become one of the most popular events for distance runners (e.g. Aschmann et al., 2013; Hanc, 2008), and the International Association of Athletics Federations (IAAF) inaugurated the first World Half Marathon Championships in 1992 (IAAF, 2014). The World Half Marathon Championships incorporate a team competition where team positions are based on cumulative finishing times rather than individuals' finishing positions (IAAF, 2013). The duration of elite-standard half marathons (approximately 60 minutes for world-class men, and 68 minutes for world-class women) makes them suitable for research on endurance performance (e.g. Burke, Wood, Pyne, Telford, \& Saunders, 2005; Hasegawa, Yamauchi, \& Kraemer, 2007; Larson et al., 2011), but no studies have examined the pacing profiles adopted by elite-standard half marathon runners despite their importance to optimising an individual's performance (Abbiss \& Laursen, 2008).

Pacing strategies can be categorised as positive pacing (the athlete's speed decreases during the competition), negative pacing (the athlete speeds up), even pacing (a stable speed is maintained), variable pacing (speed is varied throughout), and parabolic-shaped pacing (greater speeds occur at the start and finish) (Abbiss \& Laursen, 2008; de Koning et al., 2011). It has been suggested that an even pacing profile is the best for prolonged activity (e.g. Abbiss \& Laursen, 2008). Support for such a profile was shown in a track-cycling world record time-trial of similar duration to a world-class half marathon (Padilla, Mujika, Angulo, \& Goiriena, 2000). However, the nature of direct competition means that athletes often purposefully deviate from an even pace for tactical reasons (Hanley, 2013), with parabolicshaped pacing a common result of this. Two types of parabolic-shaped pacing that have been identified are $\mathrm{J}$-shaped (the finishing pace is greater than the starting pace), and reverse $\mathrm{J}$ - 
shaped (the starting pace is greater than the finishing pace) (Abbiss \& Laursen, 2008). These types of pacing tend to occur because many distance runners follow the lead pace during the early stages of the race before slowing to more sustainable speeds relative to their ability (Hanley, 2014; Thiel, Foster, Banzer, \& de Koning, 2012), which means they can still finish the race, and often increase pace once they know they are nearing the end of competition (de Koning et al., 2011; Swart et al., 2009).

The decision to follow the behaviour of rivals at the commencement of competition might occur because it is the easiest choice when rewards are based on finishing position (Renfree \& St Clair Gibson, 2013). However, athletes might not follow the pace set by the leaders but instead form packs with others they believe have similar abilities or ambitions, or with those they find are running at a similar pace during the course of the actual race. Forming packs is considered important in triathlons, particularly during the cycling section because of the benefits of drafting (Fleck, Bentley, Millet, \& Bürgi, 2008; Peeling, Bishop, \& Landers, 2005), and it is possible that benefits also accrue in distance running events such as the half marathon. Indeed, one advantage for the pack runner could include using other athletes as external references for pacing (Renfree, Martin, Micklewright, \& St Clair Gibson, 2014), and the study of how well packs of runners perform in elite-standard competition could be of benefit to athletes and coaches in developing pre-race strategies.

Pacing strategies are an important factor in optimal endurance performance, and the nature of the half marathon event allows study of pacing profiles used by athletes of varying abilities and finishing positions. The shorter duration of half marathons compared with the full marathon means that nutritional strategies during the race (whose influences are difficult to measure) are not as important (Burke et al., 2005). Instead, the duration of the competition 
might mean that any packing strategies used are important to the pacing profiles adopted, and should be studied so that potentially beneficial approaches to packing are identified and can be recommended to coaches. The aim of this study was to describe the pacing profiles adopted by elite-standard athletes competing in the IAAF World Half Marathon Championships, with regard to both competition performance and packing behaviour.

\section{METHODS}

\section{Participants}

The Faculty Research Ethics Committee approved the study. Finishing and split times were obtained from the open-access IAAF website (IAAF, 2014) for competitors in the men's and women's races at the six IAAF World Half Marathon Championships held between 2007 and 2014 (the competition was held annually until 2010, after which it became a biennial event) (Table 1). A total of 491 men and 347 women were analysed across all six competitions (including athletes competing more than once). The performances of 23 men and 16 women who did not finish, and of 23 men and 25 women considered very slow (i.e. with a finishing time more than $25 \%$ greater than the winner's time), were omitted.

**** Table 1 near here $* * * *$

\section{Data Analysis}

The study was designed as observational research in describing pacing profiles. Race split times were obtained at $5 \mathrm{~km}, 10 \mathrm{~km}, 15 \mathrm{~km}, 20 \mathrm{~km}$ and the finish $(21.098 \mathrm{~km})$, and the mean speed for each of these five segments calculated. For convenience, the final segment distance is described as $1.1 \mathrm{~km}$. Competitors in each race were first divided into five groups based on finishing times, and each athlete was placed in only one group. These groups were medallists 
(a total of 18 men and 18 women); non-medallists whose finishing times were within 5\% of the winner's time in their respective races (the 5\% group: 110 men; 73 women); athletes whose finishing times were between $6 \%$ and $10 \%$ slower than the winner's time (the $6-10 \%$ group: 191 men; 123 women); athletes whose finishing times were between $11 \%$ and 15\% slower than the winner's time (the 11-15\% group: 101 men; 77 women); and athletes whose finishing times were between $16 \%$ and $25 \%$ slower than the winner's time (the $16-25 \%$ group: 71 men; 56 women). All finishing time percentages were rounded to the nearest integer before athletes were allocated to a group.

The second part of the analysis investigated the pacing profiles of runners identified as running alone or in a pack. Athletes were considered to be in a pack when the split time difference between consecutive athletes was $1 \mathrm{~s}$ or less (at the intermediate splits, but not the finish). The pacing profiles of men and women were combined for this part of the analysis. Apart from the solo runners who were identified as never running with a pack $(\mathrm{N}=98)$, five types of pack were defined: ever-present packs, where all pack members were together at all four splits $(\mathrm{N}=112)$; nomadic packs, where all athletes were in packs at the four splits, but not with the same competitors $(\mathrm{N}=118)$; halfway packs, where all athletes ran together in the same pack until 10 or $15 \mathrm{~km}(\mathrm{~N}=337)$; regrouping packs, where athletes were in a pack at 5 $\mathrm{km}$, isolated at $10 \mathrm{~km}$, but re-joined a pack at $15 \mathrm{~km}(\mathrm{~N}=70)$; and short-lived packs, where athletes were in a pack at $5 \mathrm{~km}$ and then ran the rest of the race alone $(\mathrm{N}=103)$. The number of athletes from each group (e.g. medallists) in each type of pack is shown in Table 2. To compare the pacing profiles of the solo runners and packs with one another, each athlete's mean speed for the first $5 \mathrm{~km}$ was expressed as $100 \%$ and each subsequent mean segment speed expressed as a percentage of the initial $5 \mathrm{~km}$ speed. 
$* * * *$ Table 2 near here $* * * *$

\section{Statistical analysis}

One-way repeated-measures ANOVAs compared mean speeds of each group with repeated contrast tests conducted to identify changes between successive race segments (Field, 2009). Greenhouse-Geisser corrections were used if Mauchly's test for sphericity was violated. In addition, one-way ANOVAs with Tukey's post-hoc tests compared mean segment speeds between groups and mean percentages between packs (Field, 2009). The percentage data were arcsine transformed for the purposes of statistical analysis (Hanley, 2014). The percentage change in pace between the first and second $10 \mathrm{~km}$ distances for men and women was compared using an independent $t$-test. Statistical significance was accepted as $P<.05$. Effect sizes (ES) for differences between successive segments, and between groups during each segment, were calculated using Cohen's $d$ (Cohen, 1988) and considered to be either trivial $(\mathrm{ES}:<0.20)$, small $(0.21-0.60)$, moderate $(0.61-1.20)$, large $(1.21-2.00)$, very large $(2.01-4.00)$, or nearly perfect $(>4.00)$ (Hopkins, Marshall, Batterham, \& Hanin, 2009).

\section{RESULTS}

Mean segment speeds for each group of male athletes are shown in Figure 1. All effect sizes for differences between successive segment speeds up to $20 \mathrm{~km}$ were either moderate or large. There was a moderate effect size for the difference between the last two segments (i.e. $15-20 \mathrm{~km}$ and the final 1.1. $\mathrm{km})$ for the medallists $(\mathrm{ES}=1.19), 5 \%$ group $(\mathrm{ES}=0.83), 6-$ $10 \%$ group $(\mathrm{ES}=0.65)$, and $11-15 \%$ group $(\mathrm{ES}=0.70)$. However, the effect size between these two segments was small for the $16-25 \%$ group $(E S=0.47)$. There was no difference between the medallists and the $5 \%$ group for mean speed over the first $5 \mathrm{~km}$, although the 
medallists were already faster than the other three groups by this distance (6-10\% group: $P<$ $.001, \mathrm{ES}=1.35 ; 11-15 \%$ group: $P<.001, \mathrm{ES}=2.09 ; 16-25 \%$ group: $P<.001, \mathrm{ES}=2.86$ ). However, the medallists were faster than the $5 \%$ group at the $10 \mathrm{~km}$ distance $(P<.001, \mathrm{ES}=$ $1.18)$ and for every segment thereafter $(15 \mathrm{~km}: P<.001$, ES $=1.46 ; 20 \mathrm{~km}: P<.001$, ES $=$ 1.33; Finish: $P=.001, \mathrm{ES}=1.14)$.

$* * * *$ Figure 1 near here $* * * *$

Mean segment speeds for each group of female athletes are shown in Figure 2. Most of the effect sizes for differences between successive segment speeds were either moderate or large. However, the effect size for the difference between the third $(10-15 \mathrm{~km})$ and fourth segments $(15-20 \mathrm{~km})$ was small for the $6-10 \%$ group, and there was a small effect size for the increase in mean speed for the $11-15 \%$ group during the last $1.1 \mathrm{~km}$ segment $(\mathrm{ES}=$ 0.42 ). As with the men, there was no difference between the medallists and the $5 \%$ group for mean speed over the first $5 \mathrm{~km}$, although the medallists were already faster than the other three groups by this distance (all $P<.001)(6-10 \%$ group: $\mathrm{ES}=2.16 ; 11-15 \%$ group: $\mathrm{ES}=$ $3.57 ; 16-25 \%$ group: $\mathrm{ES}=4.34)$. However, the medallists were faster than the $5 \%$ group for the $5-10 \mathrm{~km}$ segment $(P<.001, \mathrm{ES}=1.40)$ and for every segment thereafter $(15 \mathrm{~km}: P<$ $.001, \mathrm{ES}=1.55 ; 20 \mathrm{~km}: P=.001, \mathrm{ES}=1.26$; Finish: $P=.002$, ES $=0.95)$. The women's second $10 \mathrm{~km}$ time was $4.7 \%( \pm 3.2)$ slower than the first, a decrease in pace that was not different from that experienced by the men $(4.9 \pm 3.7 \%)$.

$* * * *$ Figure 2 near here $* * * *$ 
Pack running was prevalent both in men's and women's races, as shown by the total number forming packs in Table 3. The lead group at $5 \mathrm{~km}$ in the six men's races comprised 26, 13, $18,25,31$, and 46 athletes respectively, while in the women's races, the lead group at $5 \mathrm{~km}$ in the six races comprised 10, 8, 6, 10,6, and 22 athletes respectively. Differences in segment pace relative to the opening $5 \mathrm{~km}$ pace are shown in Figure 3 . At $10 \mathrm{~km}$, the ever-present, nomadic and halfway packs all had higher segment pace percentages than the solo runners, regrouping and short-lived packs $(P<.01)$, with no differences within either set of three groups. Effect sizes were all moderate except for the difference between the halfway packs and the regrouping packs $(E S=0.54)$. At $15 \mathrm{~km}$, the ever-present and nomadic packs did not differ in segment pace percentage, but the halfway packs did have a lower percentage than the ever-present packs $(P=.001, \mathrm{ES}=0.46)$. All three of the ever-present, nomadic and halfway packs had a greater segment pace percentage than the other three packs $(P \leq .001)$. All effect sizes were moderate except for the difference between the halfway packs and the solo runners $(\mathrm{ES}=0.43)$. At $20 \mathrm{~km}$, there was no difference between the percentages of the ever-present and nomadic packs, but they had higher percentages than the solo runners, regrouping and short-lived packs $(P<.001)$. All effect sizes were moderate except for the difference between the nomadic packs and the solo runners $(E S=0.54)$. There was also a difference between the ever-present and halfway packs $(P<.001)$ but the effect size was small $(\mathrm{ES}=0.55)$. With regard to the final $1.1 \mathrm{~km}$ segment, the ever-present packs' mean split was the only one faster than their original $5 \mathrm{~km}$ split, and their percentage was higher than all of the other packs and solo runners $(P<.001$, ES between 0.77 and 1.19). There were no differences between any of the other packs. The mean difference in the finishing times between runners in the ever-present packs was $6 \mathrm{~s}( \pm 6)$, with 12 of the 45 ever-present packs separated by $1 \mathrm{~s}$ or less at the end of the race; 10 of these 45 packs comprised entirely athletes of the same nationality. 
$* * * *$ Table 3 near here $* * * *$

$* * * *$ Figure 3 near here $* * * *$

\section{DISCUSSION}

The aim of this study was to describe the pacing profiles adopted by competitors at the IAAF World Half Marathon Championships. The first objective was to examine pacing profiles of athletes grouped by performance, and the results showed that nearly all groups had parabolicshaped (reverse-J) pacing profiles. These profiles occurred because most athletes completed the initial $5 \mathrm{~km}$ segment relatively quickly, slowed progressively until $20 \mathrm{~km}$, and then sped up considerably during the final $1.1 \mathrm{~km}$ segment. However, higher-placed finishers did not slow down to the same extent after $5 \mathrm{~km}$ or with the same profile, as the male medallists were faster at $10 \mathrm{~km}$ than at $5 \mathrm{~km}$ (and maintained their speed to $15 \mathrm{~km}$ ), while the men's $5 \%$ group maintained their initial $5 \mathrm{~km}$ pace to $10 \mathrm{~km}$. In addition, the female medallists did not slow between $10 \mathrm{~km}$ and $15 \mathrm{~km}$. The differences in pacing profiles between faster and slower finishers showed that there are possible benefits in maintaining an even pace, but for many athletes to achieve this requires a slower start, based on more realistic expectations of finishing time. Nonetheless, performance benefits of a slower starting speed are reduced rates of carbohydrate depletion, lower excessive oxygen consumption, lower blood lactate concentrations and ultimately a better finishing time (Abbiss \& Laursen, 2008).

One reason why athletes start too quickly is because they follow the lead pace regardless of their ability or predicted finishing time (Hanley, 2014; Thiel et al., 2012). In addition, a quick pace might be adopted at the start because the athletes' rating of perceived exertion (RPE) is 
less than anticipated (because they are not yet fatigued or because of race excitement) (de Koning et al., 2011; Renfree et al., 2014), or because they simply do not know how well they will run on that particular occasion and decide to try for their best possible performance. The second part of this study that investigated packing behaviour showed that the lead group typically contained a substantial number of runners at $5 \mathrm{~km}$; however, most athletes running in packs at this distance were not actually in the lead group, and the slower groups of athletes were already slower than the faster athletes by $5 \mathrm{~km}$. Instead, athletes tended to form packs with others of similar ability, although the packs themselves frequently changed composition throughout the race. The most important finding was that those athletes who ran in packs for practically the whole race (the ever-present and nomadic packs) slowed the least relative to their opening $5 \mathrm{~km}$ pace, and the ever-present packs were the only ones to run the final 1.1 $\mathrm{km}$ at a greater mean speed than that of their first $5 \mathrm{~km}$. The smaller reductions in pace and faster finish for the ever-present packs was possibly because the athletes were able to use each other as pacemakers (Renfree et al., 2014), which might have occurred as the race progressed or have been pre-planned (many of the ever-present packs contained athletes from the same nation, and two comprised sets of twins). Hence, there might be an advantage of running in packs to achieve an even pace, either through staying with the same athletes throughout, or by moving between packs (by catching up to others, or slowing down to be absorbed by a chasing group).

Although there appears to be a benefit to running as part of a pack throughout the half marathon, the results showed that those who dropped off the pace after $5 \mathrm{~km}$ (the short-lived and regrouping packs) had the least even-paced profiles, slowing to approximately $91 \%$ of their $5 \mathrm{~km}$ speed at $20 \mathrm{~km}$. In general, these packs' pacing profiles were no better than those who never ran with a pack at all, and showed that there was no advantage in keeping up with 
a pack to $5 \mathrm{~km}$ if it then meant being quickly dropped from that pack (and that regrouping by $15 \mathrm{~km}$ did not make up for too fast a start). By contrast, those athletes who were able to remain in a pack until after $10 \mathrm{~km}$ (the halfway packs) did not slow as badly and indeed had similar pacing profiles to the nomadic packs. Starting the race at the correct pace, so as to avoid slowing too quickly, might therefore include choosing the right opponents to run with from the outset. While this will most likely be the lead group for those who aim to win a medal, athletes with more modest aims (e.g. doing as well as possible in the team competition) could start more conservatively than the lead group and try to identify packs that are more in line with their ability.

One noticeable feature of this study was that all groups, regardless of finishing time, reduced mean speed between 15 and $20 \mathrm{~km}$, but still increased pace during the final $1.1 \mathrm{~km}$. As in previous research on other endurance events (e.g. de Koning et al., 2011; Hanley, 2013), this indicates that athletes experienced a positive affective response (Renfree et al., 2014) by knowing they were nearing the finish and thus were able to produce a fast finish despite fatigue. However, many athletes might not be overly fatigued by $15 \mathrm{~km}$, and instead it is possible that some deliberately slowed between 15 and $20 \mathrm{~km}$ to try to run below their critical speed (i.e. the speed above which finite, predominantly nonoxidative exercise is performed (Burnley \& Jones, 2010)) so that these metabolic reserves were used during the fast finish instead. This tactic certainly appears to have been used by the ever-present packs, as athletes in these packs reduced their pace to the exact same speed as others alongside them, before engaging in head-to-head competition during the last $1.1 \mathrm{~km}$. For most athletes the reward for this was simply to finish ahead of their nearest rivals, despite it being a poor overall tactic for those in the minor positions where the most sensible strategy would have been to achieve the best possible time with regard to the team competition. However, it was 
notable that nearly half of all medals were won by athletes using this tactic and emphasises the importance of the sprint finish in world-class distance running (Thiel et al., 2012), even over the half marathon distance. The best athletes who are likely to win a medal and know they have an exceptionally fast finish are therefore advised to identify their main rivals early in the race and match their pace until close to the end. Conversely, it is recommended that top athletes who frequently struggle during the sprint finish should try to break away from faster finishers, or to reduce their opponents' capacity for a fast finish by continuing to run at an even pace to $20 \mathrm{~km}$.

There are several key findings in this study that could be used by athletes and coaches in preparing for competition. The best athletes adopted even pacing for at least some of the race, and slowing down between 15 and $20 \mathrm{~km}$ might be helpful in producing a faster final $1.1 \mathrm{~km}$. This seemed important not just for the medallists, but also in battles for the minor positions (in achieving "mid-pack supremacy" and "tail-end dominance" (Onions, 1996)). In terms of pre-race strategies, identifying other athletes (including teammates) who are likely to run at a similar pace throughout is a sensible tactic because those athletes can be used as pacemakers. In contrast, completing the first $5 \mathrm{~km}$ at the same pace as superior athletes can result in rapid and continued slowing down. Moving from one pack to another if the pace is unsuitable (nomadic packing) can also be advantageous if managed successfully. Overall, men and women slowed to the same degree during the second $10 \mathrm{~km}$, and coaches can thus advise athletes of either sex to consider these tactics. It should be noted that data were available only for each $5 \mathrm{~km}$ split and the finish, and this study therefore presents macrovariations (Hanley, 2014) in terms of changes in pace and the presence of packs. Future research could benefit from higher resolution data so that the formation and break-up 
of these packs is explained in more detail, and lead to greater understanding of the advantages of adopting this tactic.

\section{CONCLUSIONS}

This study investigated pacing profiles and packing behaviour in the IAAF World Half Marathon Championships. The best athletes displayed patterns of even pacing for some of the race, while slower athletes generally slowed from a peak speed at $5 \mathrm{~km}$ until they reached $20 \mathrm{~km}$. All groups increased pace considerably during the final $1.1 \mathrm{~km}$, and this might have been facilitated by their reduced paces in the $5 \mathrm{~km}$ segment immediately before this. Staying in a pack was beneficial for reducing decreases in pace after $5 \mathrm{~km}$, although athletes need to be careful not to start with a pack whose pace is unsuitably fast for them. Coaches and athletes are advised to prepare pre-race strategies that incorporate pack running by identifying suitable rivals to use as pacemakers, while considering the best end-race strategy that takes into account the individual's sprint finish. 


\section{REFERENCES}

Abbiss, C. R., \& Laursen, P. B. (2008). Describing and understanding pacing strategies during athletic competition. Sports Medicine, 38, 239-252. doi: 10.2165/00007256200838030-00004

Aschmann, A., Knechtle, B., Cribari, M., Rüst, C. A., Onywera, V., Rosemann, T., \& Lepers, R. (2013). Performance and age of African and non-African runners in half- and full marathons held in Switzerland, 2000-2010. Open Access Journal of Sports Medicine, 4, 183192. doi: 10.2147/OAJSM.S45918

Burke, L. M., Wood, C., Pyne, D. B., Telford, R. D., \& Saunders, P. U. (2005). Effect of carbohydrate intake on half-marathon performance of well-trained runners. International Journal of Sport Nutrition and Exercise Metabolism, 15, 573-589. Retrieved from http://journals.humankinetics.com/ijsnem-backissues/IJSNEMVolume15Issue6December/EffectofCarbohydrateIntakeonHalfMarathonPerfo rmanceofWellTrainedRunners

Burnley, M., \& Jones, A. M. (2010). 'Traditional' perspectives can explain the sprint finish. In: Comments on Point:Counterpoint: Afferent feedback from fatigued locomotor muscles is/is not an important determinant of endurance exercise performance. Journal of Applied Physiology, 108, 458-468. doi: 10.1152/japplphysiol.01388.2009

Cohen, J. (1988). Statistical power analysis for the behavioural sciences $\left(2^{\text {nd }}\right.$ ed.). Hillsdale, NJ: Lawrence Erlbaum. 
de Koning, J. J., Foster, C., Bakkum, A., Kloppenburg, S., Thiel, C., Joseph, T., Cohen, J., \& Porcari, J. P. (2011). Regulation of pacing strategy during athletic competition. PLoS ONE, 6(1), e15863. doi: 10.1371/journal.pone.0015863

Field, A. P. (2009). Discovering statistics using SPSS (3rd ed.). London: Sage.

Fleck, V. E., Bentley, D. J., Millet, G. P., \& Bürgi, A. (2008). Pacing during an elite Olympic distance triathlon: comparison between male and female competitors. Journal of Science and Medicine in Sport, 11, 424-432. doi: 10.1016/j.jsams.2007.01.006

Hanc, J. (2008). Sometimes half is better than whole. Retrieved from http://www.nytimes.com/2008/07/24/fashion/24fitness.html?_r=0

Hanley, B. (2014). Senior men's pacing profiles at the IAAF World Cross Country Championships. Journal of Sports Sciences, 32, 1060-1065. doi: $10.1080 / 02640414.2013 .878807$

Hanley, B. (2013). An analysis of pacing profiles of world-class racewalkers. International Journal of Sports Physiology and Performance, 8, 435-441. Retrieved from http://journals.humankinetics.com/ijspp-back-issues/ijspp-volume-8-issue-4-july/an-analysisof-pacing-profiles-of-world-class-racewalkers

Hasegawa, H., Yamauchi, T., \& Kraemer, W. J. (2007). Foot strike patterns of runners at the 15-km point during an elite-level half marathon. Journal of Strength and Conditioning Research, 21, 888-893. Retrieved from http://journals.lww.com/nsca- 
jscr/Abstract/2007/08000/FOOT_STRIKE_PATTERNS_OF_RUNNERS_AT_THE_15_KM POINT.40.aspx

Hopkins, W. G., Marshall, S. W., Batterham, A. M., \& Hanin, J. (2009). Progressive statistics for studies in sports medicine and exercise science. Medicine and Science in Sports and Exercise, 41, 3-12. doi: 10.1249/MSS.0b013e31818cb278

IAAF (2013). Competition rules 2014-15. Monte Carlo, Monaco: IAAF.

IAAF (2014). Competition archive. $\quad$ Retrieved from http://www.iaaf.org/results?\&subcats=WXC

Larson, P., Higgins, E., Kaminski, J., Decker, T., Preble, J., Lyons, D., McIntyre, K., \& Normile, A. (2011). Foot strike patterns of recreational and sub-elite runners in a longdistance road race. Journal of Sports Sciences, 29, 1665-1673. doi: $10.1080 / 02640414.2011 .610347$

Onions, B. (1996). Local heroes. Runner's World UK, 4(1), 106.

Padilla, S., Mujika, I., Angulo, F., \& Goiriena, J. J. (2000). Scientific approach to the 1-h cycling world record: a case study. Journal of Applied Physiology, 89, 1522-1527. Retrieved from http://jap.physiology.org/content/89/4/1522 
Peeling, P. D., Bishop, D. J., \& Landers, G. J. (2005). Effect of swimming intensity on subsequent cycling and overall triathlon performance. British Journal of Sports Medicine, 39, 960-964. doi: 10.1136/bjsm.2005.020370

Renfree, A., Martin, L., Micklewright, D., \& St Clair Gibson, A. (2014). Application of decision-making theory to the regulation of muscular work rate during self-paced competitive endurance activity. Sports Medicine, 44, 147-158. doi: 10.1007/s40279-0130107-0

Renfree, A., \& St Clair Gibson, A. (2013). Influence of different performance levels on pacing strategy during the women's World Championship marathon race. International Journal of Sports Physiology and Performance, 8, 279-285. Retrieved from http://journals.humankinetics.com/ijspp-back-issues/ijspp-volume-8-issue-3-may/influenceof-different-performance-levels-on-pacing-strategy-during-the-womens-worldchampionship-marathon-race

Swart, J., Lamberts, R. P., Lambert, M. I., Lambert, E. V., Woolrich, R. W., Johnston, S., \& Noakes, T. D. (2009). Exercising with reserve: exercise regulation by perceived exertion in relation to duration of exercise and knowledge of endpoint. British Journal of Sports Medicine, 43, 775-781. doi: 10.1136/bjsm.2008.056036

Thiel, C., Foster, C., Banzer, W., \& de Koning, J. (2012). Pacing in Olympic track races: competitive tactics versus best performance strategy. Journal of Sports Sciences, 30, 11071115. doi: 10.1080/02640414.2012.701759 
Table 1. Details of each analysed competition.

\begin{tabular}{|c|c|c|c|c|}
\hline \multirow[b]{2}{*}{ Venue } & \multicolumn{3}{|c|}{ Finishers } & \multirow{2}{*}{$\begin{array}{l}\text { Winning time } \\
\text { (h:min:s) }\end{array}$} \\
\hline & Year & $(\mathrm{N})$ & Gold medallist & \\
\hline \multicolumn{5}{|c|}{ Men } \\
\hline Debrecen (Hungary) & 2007 & 79 & Tadese (Eritrea) & $58: 59$ \\
\hline Rio de Janeiro (Brazil) & 2008 & 86 & Tadese (Eritrea) & $59: 56$ \\
\hline Birmingham (Great Britain) & 2009 & 94 & Tadese (Eritrea) & $59: 35$ \\
\hline Nanning (China) & 2010 & 68 & Kiprop (Kenya) & 1:00:07 \\
\hline Kavarna (Bulgaria) & 2012 & 78 & Tadese (Eritrea) & 1:00:19 \\
\hline Copenhagen (Denmark) & 2014 & 109 & Kamworor (Kenya) & $59: 08$ \\
\hline \multicolumn{5}{|c|}{ Women } \\
\hline Debrecen (Hungary) & 2007 & 56 & Kiplagat (Netherlands) & $1: 06: 25$ \\
\hline Rio de Janeiro (Brazil) & 2008 & 60 & Kiplagat (Netherlands) & $1: 08: 37$ \\
\hline Birmingham (Great Britain) & 2009 & 58 & Keitany (Kenya) & $1: 06: 36$ \\
\hline Nanning (China) & 2010 & 51 & Kiplagat (Kenya) & $1: 08: 24$ \\
\hline Kavarna (Bulgaria) & 2012 & 59 & Hailu (Ethiopia) & $1: 08: 55$ \\
\hline Copenhagen (Denmark) & 2014 & 88 & Cherono (Kenya) & $1: 07: 29$ \\
\hline
\end{tabular}


Table 2. Number of athletes from the performance groups in each type of pack.

\begin{tabular}{lcccccc}
\hline & Ever- & Nomadic & Halfway & Regroupers & Short-lived & Solo \\
& present & & & & & \\
\hline Medallists & 16 & 3 & 13 & 1 & 3 & 0 \\
$5 \%$ & 37 & 30 & 85 & 12 & 11 & 8 \\
$6-10 \%$ & 49 & 66 & 122 & 30 & 18 & 29 \\
$11-15 \%$ & 8 & 13 & 88 & 11 & 32 & 26 \\
$16-25 \%$ & 2 & 6 & 29 & 16 & 39 & 35 \\
\hline
\end{tabular}


Table 3. Number and percentage of athletes running in packs at each $5 \mathrm{~km}$ split.

\begin{tabular}{|c|c|c|c|c|c|}
\hline Year & Total & $5 \mathrm{~km}$ & $10 \mathrm{~km}$ & $15 \mathrm{~km}$ & $20 \mathrm{~km}$ \\
\hline \multicolumn{6}{|c|}{ Men } \\
\hline 2007 & 77 & 67 (87\%) & $67(87 \%)$ & $53(69 \%)$ & $51(66 \%)$ \\
\hline 2008 & 76 & $72(95 \%)$ & $47(62 \%)$ & $48(63 \%)$ & $26(34 \%)$ \\
\hline 2009 & 93 & $87(94 \%)$ & $78(84 \%)$ & $62(67 \%)$ & $50(54 \%)$ \\
\hline 2010 & 65 & $58(89 \%)$ & $49(75 \%)$ & $47(72 \%)$ & $28(43 \%)$ \\
\hline 2012 & 74 & $69(93 \%)$ & $49(66 \%)$ & $45(61 \%)$ & $27(36 \%)$ \\
\hline 2014 & 106 & $99(93 \%)$ & $87(82 \%)$ & $72(68 \%)$ & $65(61 \%)$ \\
\hline \multicolumn{6}{|c|}{ Women } \\
\hline 2007 & 53 & $41(77 \%)$ & $35(66 \%)$ & $31(58 \%)$ & $23(43 \%)$ \\
\hline 2008 & 53 & $44(83 \%)$ & $31(58 \%)$ & $27(51 \%)$ & $13(25 \%)$ \\
\hline 2009 & 55 & $43(78 \%)$ & $39(71 \%)$ & $19(35 \%)$ & $17(31 \%)$ \\
\hline 2010 & 49 & $39(80 \%)$ & $29(59 \%)$ & $19(39 \%)$ & $15(31 \%)$ \\
\hline 2012 & 56 & $46(82 \%)$ & $37(66 \%)$ & $19(34 \%)$ & $8(14 \%)$ \\
\hline 2014 & 81 & $75(93 \%)$ & $62(77 \%)$ & $46(57 \%)$ & $39(48 \%)$ \\
\hline
\end{tabular}




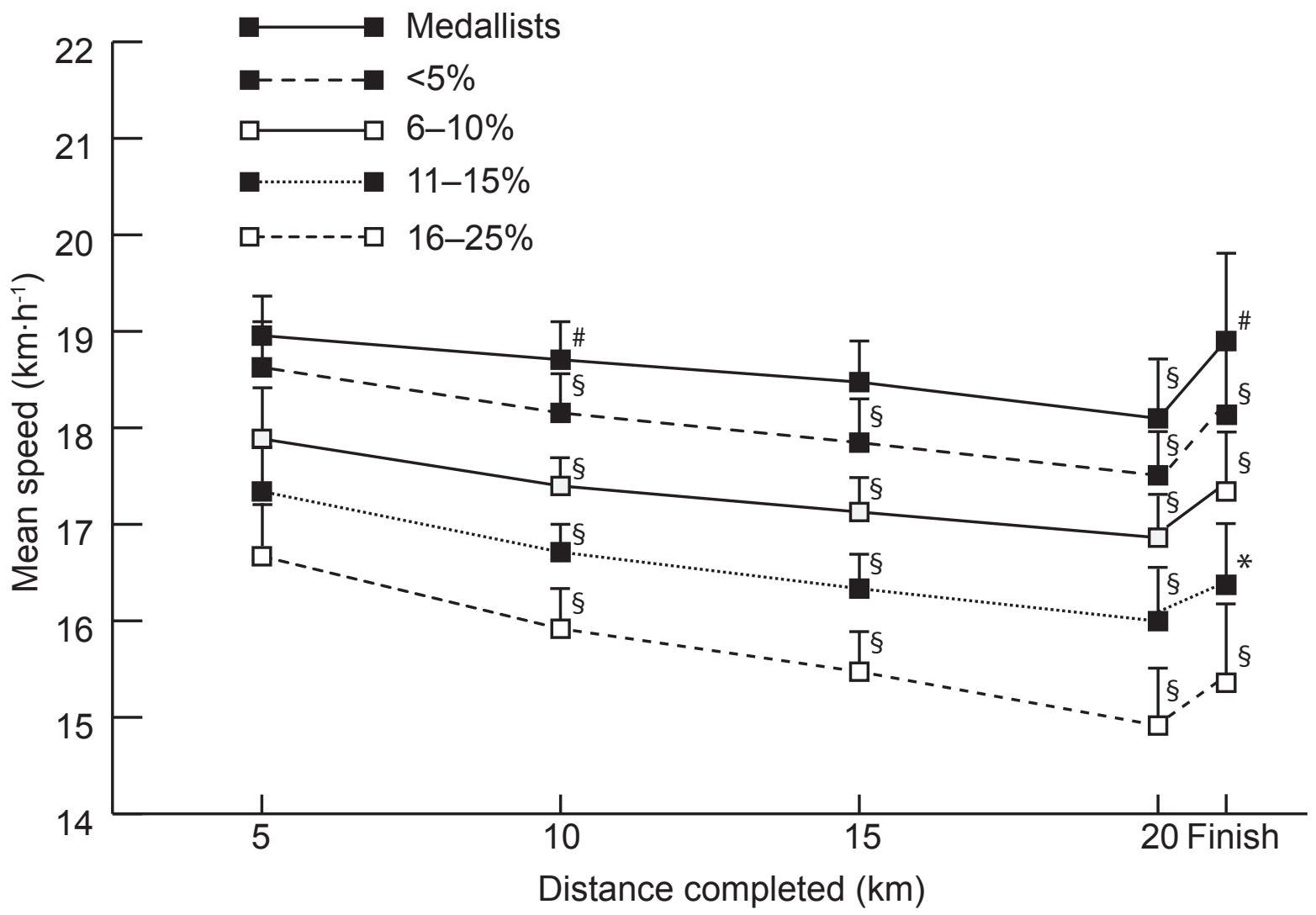




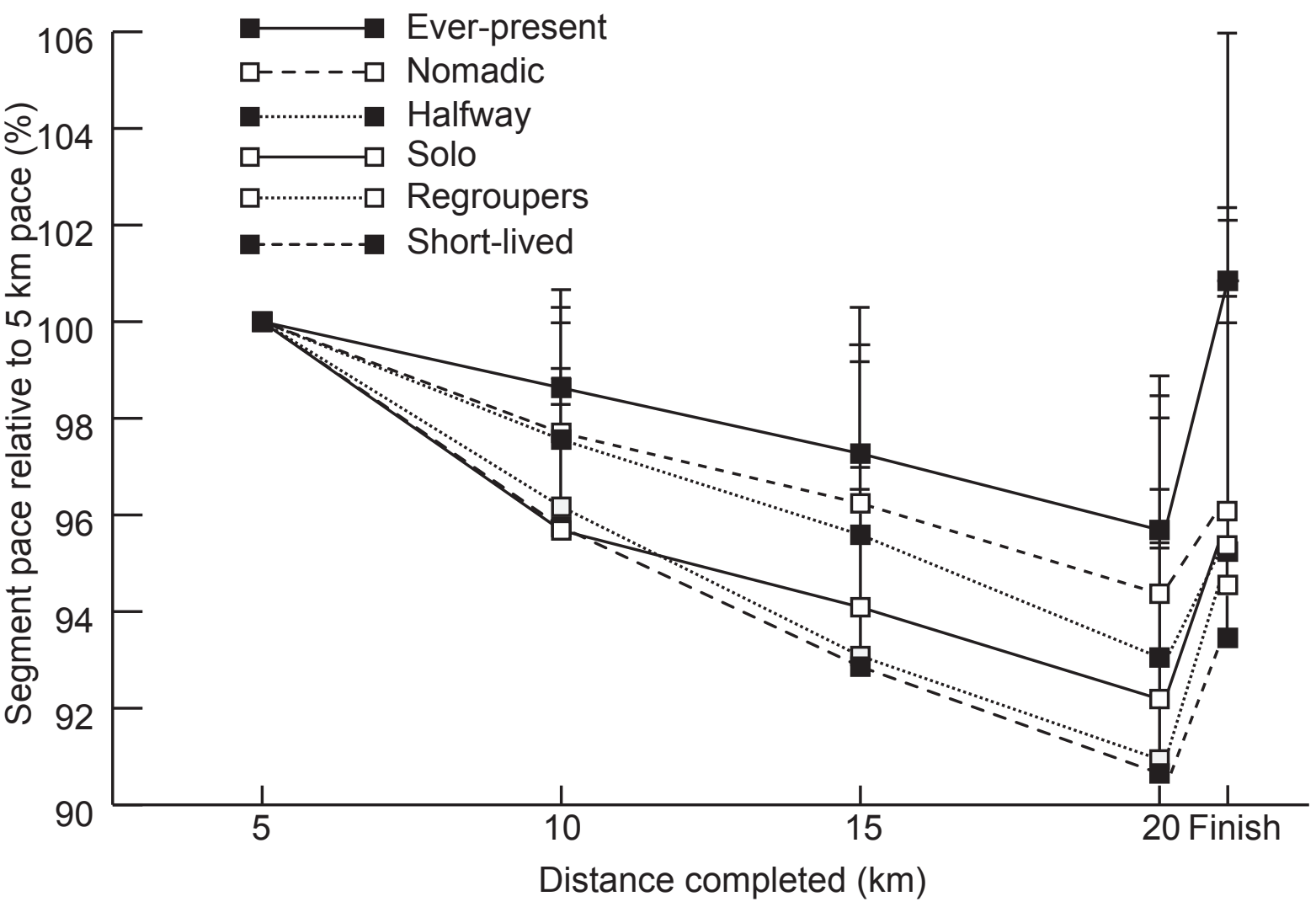

